\title{
Procurement Transformation in Digital World
}

\author{
Josef Č́í̌ ${ }^{1,}$, Michaela Krechovská ${ }^{1}$, and Alena Palacká ${ }^{1 *}$ \\ ${ }^{1}$ University of West Bohemia, Faculty of Eonomics, Department of Finance and Accounting, \\ Univerzitni 22, 30614 Pilsen, Czech Republic
}

\begin{abstract}
Technological development and progress in digitization permeate all areas of life, of course not excluding companies and their activities and individual business processes. In this paper, we focus on the area of corporate procurement as one of the key areas for fulfilling corporate goals and its transformation in the age of digitalization. The paper aims to identify the changing function of procurement and possible opportunities of digitalization for the development of procurement and its role in organization. As the results shown, procurement is a value-creating process that is changed by the digitalization. It is moving from a traditional focus on cost reduction to value creation through dynamic cooperation and building relationships with business partners. Procurement is beginning to play an increasingly strategic role in organizations. It becomes a partner to support business efficiency and the creation of new business models.
\end{abstract}

\section{Introduction}

Procurement includes functions like as purchasing and supply management, along with managing inbound and outbound logistics [1]. Capgemini [2] define procurement as a complete process from sourcing to accounts payable (known also as Source-to-Pay). It is one of the key business areas that affects corporate profitability and the fulfilment of corporate goals. Yang et al. [3] confirm the evidence of a link between procurement strategy and corporate strategy in European and U.S. firms.

In recent years, one of the main topics addressed in the field of corporate procurement is the issue of cost reduction. Procurement is considered as the main cost driver for the organization [4] and cost reductions in the procurement process can have a high effect on the company's profit [5]. However, the traditional procurement and its function is evolving. Recently, we can come across concepts such as Digital procurement or Procurement 4.0. It is important to respond to the coming changes and think about new opportunities and possibilities for companies and procurement evolution.

The aim of the paper is to identify the changing function of procurement and possible opportunities of digitalization for the development of procurement and its role in organization.

\footnotetext{
*Corresponding author: astankov@,fek.zcu.cz
} 


\section{Methods}

First, we will focus on the analysis of procurement development, then we will discuss its transformation through digitalization. Attention will be focused also on the necessary technical solution. The analysis of the results of published studies and research will be widely used to identify the development of procurement and the opportunities that digitization brings in this area. Subsequent synthesis of knowledge will lead to the identification of these trends. Last but not least, a case study of the implementation of a new IT system in a selected multinational company will be presented. The case study will complement the paper as an example of a solution for procurement that enables the connectivity of international teams.

\section{Results and Discussion}

\subsection{Evolution of procurement}

The development of procurement since the early 1980s is shown in the Figure 1. When we look at procurement evolution, procurement has become more sophisticated and his function's role was changed from transactional management to strategic sourcing. An interesting turning point occurs mainly in the second stage of e-procurement with the onset of electronic inquiries, e-auctions, e-catalogs, etc. Today process monitoring and reporting are improving and digital procurement enabling to improve efficiencies with advanced analytics, data-driven optimization and automation tools. The focus of procurement will be on collaboration with external partners to create new, innovative business models [6]. Detailed characteristics of developmental stages can be seen in the following figure.

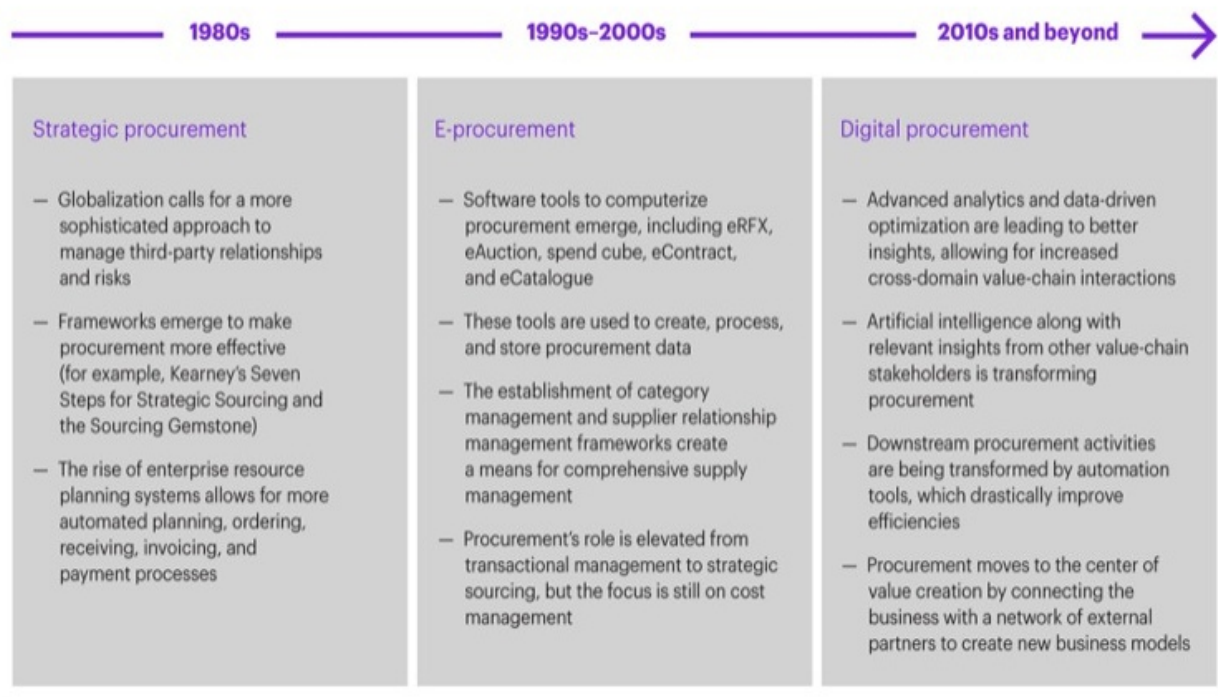

Fig. 1. Procurement evolution [6]

The development of procurement and its role goes hand in hand with the development of IT systems used for procurement. According to the Glass and Kleemann [7], The application of IT systems has developed since the 1970s, where the demand for production materials used MRP system known as "Material Requirements Planning". This system enabled to connect production and procurement. In 1975, about 700 companies had 
implemented MRP, in 1981 it was already around 8,000 companies [8, 9]. Processing took place on mainframe computers, usually once a week, data were entered using punched labels and people received the results on printed reports. Another improvement was MRP II. In fact, the functionality of the existing system has been improved.

The next stage of IT use in procurement was ERP phase, known as "Enterprise Resource Planning", that offered mainly other options and modules and was so universal that their functions covered the needs of most companies. The main advantage was in stronger cross-company integration of IT systems, providing a common basis for all major business functions across a company, spanning from sales over finance, again production (and others) to procurement [7].

E-Procurement is a term used for electronic purchasing solutions. It is software that allows you to address and select suppliers and possibly the purchase itself. Overhead materials, commodities and services are most often purchased using the e-Procurement solution. It takes place in a business relationship between two companies (B2B). The system is widely used for E-Auctions, E-Inquiries, Request for quotation. E-Procurement has been broadly adopted in organizations [10].

Reflecting the effects of Industry 4.0, new technologies and data management, we get to other development stage and Procurement 4.0 is appeared. Procurement 4.0 is a relatively new term and was introduced recently [11]. Simply said, Procurement 4.0 means application of Industry 4.0 tools in procurement.

The development of IT systems for procurement is summarized in Figure 2.

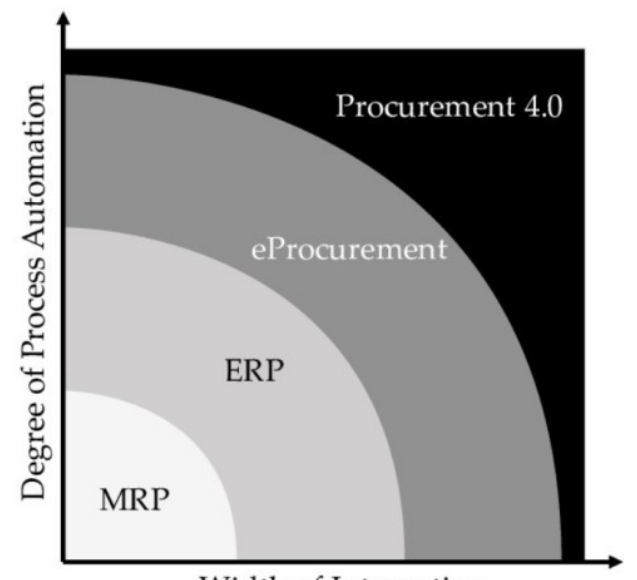

Width of Integration

Fig. 2: The evolution of procurement IT systems [7]

\subsection{Procurement transformation in digital environment}

\subsubsection{Opportunities and changing role of procurement}

We can find several definitions of digitalization, but as Parida et al. [12] points out commonly agreed definition of digitalization is currently missing. The authors view digitalizaton as "the use of digital technologies to innovate a business model and provide new revenue streams and value-producing opportunities in industrial ecosystems". We identify with the above definition and in this respect, digitalization in connection with the area of corporate procurement is also viewed. 
Procurement is a value-creating process that is changed by the digitalization. Srai et al. [13] identified fundamental principles of digitalization interventions in purchasing and supply management. Their grid provides two categories of digitalization technologies used by modern manufacturers in the procurement function: the first category is presented by basic technologies (Internet), the second category consists of advanced technologies (e.g., the use of IoT, artificial intelligence, machine learning, big data analytics, blockchain technologies, or advanced manufacturing technologies).

Procurement 4.0 contributes to the productivity goal of collaboration within Industry 4.0 and improves the organizational supply chain set up to meet tailored and innovative requirements as efficiently as possible. Thanks to new technologies Procurement 4.0 connects the companies with its suppliers and enables a dynamic cooperation and coordination of the procurement process [7]. Digitization contributes to increasing the transparency of information between partners in the supply chain. Process automation can help to reduce purchasing time and optimize resource utilization [14]. There are a huge number of ways to use digital procurement. Based on today's requirements, it is mainly about approving various workflows. Whether it is contracts or approving orders.

There are studies solving the implementation of technologies in procurement also to reduce costs, e.g. Klünder et al. [5] investigated the interrelation between digitization and procurement costs in German industry and confirm the hypothesis of cost reduction through digitization.

The digitization of procurement processes is still in its infancy in some companies. However, as some studies show $[11,2,6]$, it brings benefits in supporting day-to-day administrative and business tasks and supporting decision-making processes. The strategic role of procurement is growing. Procurement becomes a strategic partner to support business efficiency, profitability and the creation of new business models.

We can say that digitization of certain operations and processes, when aligned with the companies's core strategies, capabilities and procedures, can bring superior competitiveness [15]. Digitization offers many opportunities for companies that succeed in adapting their business models. On the other hand, not keep pace with the changing market dynamics and rapid digital processes will lead to lower profitability and represents an existential threat to the organization [16].

\subsubsection{Procurement application and IT system}

When digital transformation should reach the maximum effect, digitization should include business processes as a whole part. In the area of central purchasing, this means, for example, the management of suppliers, all type of orders. Artificial intelligence can support supply chain management. Analysing the market situation, taking into account the reliability of suppliers and proposing optimal contractual conditions, better monitor the development of individual commodities. The system can even recommend what discounts to require.

The whole process is very demanding on the volume of data. It is necessary to choose a suitable Big data platform at the beginning. The deployment platform is chosen based on: speed of computation, investment cost, ease of deployment and update, etc. [17]. It is necessary to determine the scope of digitization and choose a suitable provider. The Capgemini study [2], based on 36 providers, created an overview of possible system functionalities and compares them.

In practice, the functionality of the existing system is usually extended. We also present a case study of the implementation of a new IT system in a selected multinational company, which is currently underway in the company and will be a solution for procurement. 


\subsubsection{Case study of IT system implementation}

In Fig. 3 we see the design of key phases project of system implementation in an international company engaged in the production and distribution of alcohol. In this case study, we see the international project layout. The company currently has three manufacturing plants and several sales divisions across Europe, the company's intention is to unify processes and simply apply the model to another plant in the next probable acquisition. Due to global management in the company, some leading roles are responsible for the management of other countries, so a unified system will facilitate easier control and reporting.

The company decided to move from the SAP system to the new version of SAP S4 / HANA, so it was necessary to schedule the individual phases and set up project teams with a clear definition of powers and responsibilities. After selecting the appropriate software tool, the key phases of the project are divided in a timeline with a clear division of responsibilities. This helps to has better control in which stage of implementation we are, what the key inputs and responsibilities of individual departments will be.

The project started in 2019 and a full transition should take place in 2021. During the project, workshops are planning with participants from all participating countries. It is necessary to agree on future processes and functions that will be using, given that the company's intention is to have a unified process, often there must be compromises between countries on final solutions.

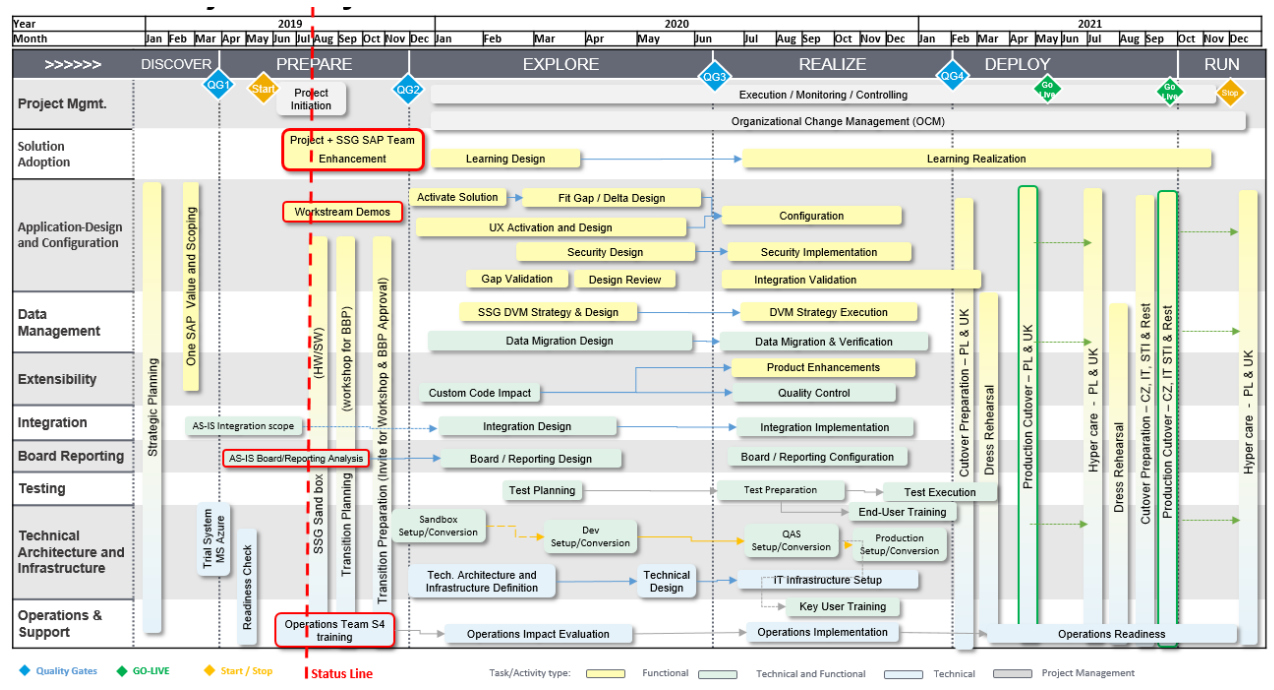

Fig. 3: Key phases of system implementation [internal source of the company]

The implementation project is divided into six basic phases. The description of individual phases is as follows:

Discover: In this section, the company decided to move to a new system. A suitable system was chosen, during a detailed analysis it was decided to expand the existing system.

Prepare: Project teams and external teams are established. Workshop dates are organized. Preparatory phases are being carried out.

Explore: December 2020 begins the first workshops for Procurement, Operations and Finance. The individual sections provide existing solutions, mostly reporting in Excel, or paper workflow, etc. During the year, the design of the future process will be set up and the first testing will take place. The technological architecture and infrastructure definition are 
chosen. Data migration design and operations impact evaluation will be proposed (Dec 2019 - Jun 2020).

Implementation: This phase includes setup and configuration, testing, data migration and verification, IT infrastructure design, key users training, Operations implementation (Jun 2020 - Jan 2021).

Deploy: This is a phase of the process called Go live. Processes in individual countries are ongoing, but external support is still being used, critical points are being sought and processes are being improved (Feb 2021 - Sep 2021).

Run: The last phase of full operation and official termination of the project (Oct 2021 Dec 2021).

\section{Conclusion}

If a company wants to be competitive and sustainable today, it must start using modern tools to simplify processes, which can be automated and eliminate the most operational part. Part of digital transformation of companies is digitalization of procurement. This will allow people in procurement to make more strategic decisions than operations.

Digital transformation requires new technologies and software concepts that allow increasing global connectivity with cross-functional teams. Technologies like Artificial Intelligence, Big Data, and Internet-of-Things enable to automate and optimise procurement model and support the organisational digital transformation.

The effectiveness of modern tools lies in the simplification of processes and the clear definition of competencies. Process automation brings the elimination of human error and joy into everyday toil with tedious administration. Centralization of all purchasing requests into one database then allows better structuring of purchases into categories. Modern tools for automation and purchasing organization do not necessarily involve complex changes in internal regulations. In the future, this phenomenon can create competitive pressure on suppliers and procurement will therefore insist on the use of digitization on their part, it can also be an exclusionary criterion in the selection of suppliers.

We conclude that the development of new technologies brings a shift in the role of procurement. Procurement is moving from a traditional focus on cost reduction to value creation through dynamic cooperation and building transparent relationships with business partners and is beginning to play an increasingly strategic role in organizations. Of course, the digital transformation of procurement requires considerable investment and is time consuming, especially in today's globalized multinational environment. However, it can bring significant value and contribute to increasing the competitiveness of companies.

\section{Acknowledgment}

The paper was created with the support of the project No. SGS-2020-026 "Economic and financial transformation in the context of digital society" which is solved at the University of West Bohemia, Faculty of Economics.

\section{References}

1. S. Bag, L. C. Wood, S. K. Mangla, S. Luthra, Procurement 4. 0 and its implications on business process performance in a circular economy. Resources, Conservation and Recycling, 152 (2020)

2. Capgemini, Digital Procurement Research 2018, Uncovering the solution that bring you forward, (2018), available at: https://www.capgemini.com/nl-nl/wp- 
content/uploads/sites/7/2018/10/Capgemini-Digital-Procurement-Research-2018_webversion1.pdf

3. C. L. Yang, R. J. Lin, D. Krumweide, E. Stickel, C. Sheu, Efficacy of purchasing activities and strategic involvement: An international comparison. International Journal of Operations \& Production Management, 33, 49-68, (2013)

4. P. Krampf, Beschaffungsmanagement, (München: Vahlen, 2014)

5. T. Klünder, J. N. Dörseln, M. Steven, Procurement 4.0: How the digital disruption supports cost-reduction in Procurement. Production, 28, (2019)

6. Kearney, Procurement: making digital transformation work for you, available at: https://www.kearney.com/procurement/article?/a/procurement-riding-thetransformative-digital-wave

7. A. H. Glas, F. C. Kleemann, The Impact of Industry 4.0 on Procurement and Supply Management: A Conceptual and Qualitative Analysis. International Journal of Business and Management Invention, 5, 55-66 (2016)

8. A. V. Mabert, The early road to material requirements planning. Journal of Operations Management, 15, 346-356, (2007)

9. S. Snapp, The History of $M R P$ and DRP, available at : https://www.brightworkresearch.com/scmhistory/2012/08/the-history-of-mrp-and$\mathrm{drp} /(2012)$

10. C. McCue, A. V. Roman, E-Procurement: Myth or Reality. Journal of Public Procurement, 12, 221-248, (2012)

11. F. Bienhaus, A. Haddud, Procurement 4.0: factors influencing the digitisation of procurement and supply chains. Business Process Management Journal, 24, 965-984 (2018)

12. V. Parida, D. Sjödin, W. Reim, Reviewing Literature on Digitalization, Business Model Innovation, and Sustainable Industry: Past Achievements and Future Promises. Sustainability, 11, (2019)

13. J. S. Srai, H. Lorentz, Developing design principles for the digitalisation of purchasing and supply management. Journal of Purchasing and Supply Management, 25, 78-98, (2019)

14. A. Telukdarie, E. Buhulaiga, S. Bag, S. Gupta, Z. Luo, Industry 4.0 implementation for multinationals. Process Safety and Environmental Protection, 118, 316-329, (2018)

15. M. Ghobakhloo, M. Fathi, Corporate survival in Industry 4.0 era: the enabling role of lean-digitized manufacturing. Journal of Manufacturing Technology Management, 31, 1-30 (2019)

16. J. Bleicher, H. Stanley, Digitization as a catalyst for business model innovation a threestep approach to facilitating economic success. Journal of Business Management, 12, 62-71, (2017)

17. De Lillo, F. Cecconi, G. Lacorata, A. Vulpiani, Sedimentation speed of inertial particles in laminar and turbulent flows. EPL, 84, 314-381 (2008) 